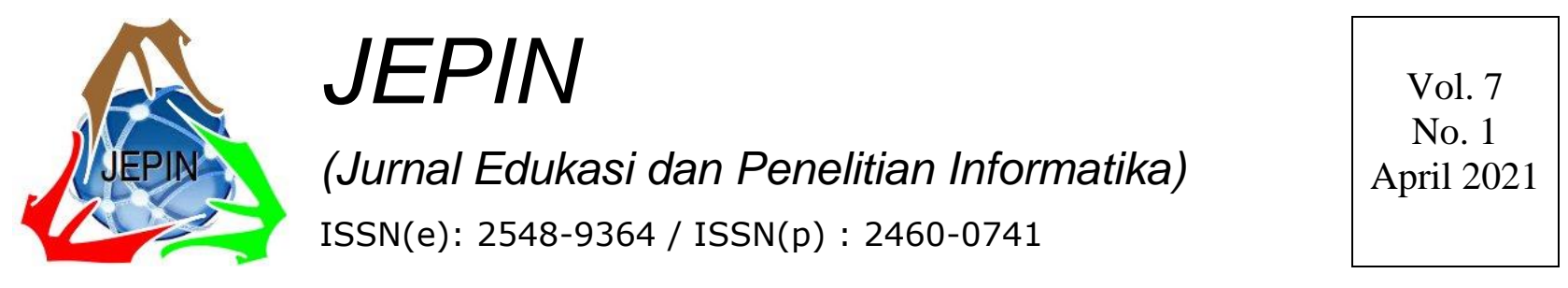

\title{
Analisis Simulasi Inverter Multilevel Kaskade dengan Teknik Selective Harmonic Elimination Pulse Width Modulation
}

\author{
Ayong Hiendro $^{\# 1}$, Ismail Yusuf ${ }^{\# 2}$ \\ ${ }^{\#}$ Teknik Elektro, Universitas Tanjungpura \\ Jalan Prof. DR. H. Hadari Nawawi, Pontianak, Indonesia \\ ${ }^{1}$ ayong.hiendrodee.untan.ac.id \\ 2ismail.yusufdee.untan.ac.id
}

\begin{abstract}
Abstrak- Salah satu teknik pengendalian saklar-saklar semikonduktor daya dari inverter multilevel adalah menggunakan Pulse Width Modulation (PWM). Dari berbagai teknik PWM, Selective Harmonic Elimination Pulse Width Modulation (SHEPWM) merupakan teknik yang andal dalam mengeliminasi harmonisa-harmonisa tingkat rendah. Tujuan dari makalah ini adalah menjabarkan proses perhitungan, perancangan dan simulasi inverter multilevel kaskade dengan menggunakan teknik SHEPWM. Pulsa-pulsa pensaklaran setiap saklar semikonduktor daya inverter dibangun berdasarkan sudut-sudut pensaklaran optimum agar komponen harmonisa tertentu dapat tereliminasi. Demikian pula gelombang tegangan AC yang dihasilkan dapat diprediksi bentuknya berdasarkan hasil rancangan. Selanjutnya simulasi komputer dilakukan dengan perantara perangkat lunak PSPICE. Analisis hasil simulasi terhadap inverter 9-level menunjukkan komponen harmonisa ke-3, 5 dan 7 tereliminasi sama sekali. Hasil ini sesuai dengan perhitungan dan perancangan secara teoritis.
\end{abstract}

Kata kunci- Indeks Modulasi, Inverter Multilevel, Pulse Width Modulation, Selective Harmonic Elimination, Sudut Pensaklaran Optimum

\section{Pendahuluan}

Seiring meningkatnya kebutuhan industri dan aplikasi pada sistem energi baru dan terbarukan (EBT) terhadap perangkat inverter bermampuan daya listrik besar yang tidak dapat dipenuhi oleh inverter 2-level [1], inverter multilevel [2] menjadi semakin menarik perhatian bagi para peneliti di bidang elektronika daya. Selain itu, di dalam aplikasi berdaya listrik besar, agar rugi-rugi pensaklaran tidak menjadi besar maka diperlukan frekwensi pensaklaran yang rendah dan hal ini mampu dipenuhi oleh inverter multilevel.

Secara umum terdapat tiga jenis topologi inverter multilevel: inverter multilevel kapasitor layang (flying capacitor multilevel inverter) [3], inverter multilevel dioda-jepit (diode-clamp multilevel inverter) [4], dan inverter multilevel kaskade (cascade multilevel inverter) [5]. Di antara semua topologi tersebut, inverter multilevel kaskade merupakan jenis yang paling banyak dipakai untuk aplikasi pada sistem-sistem EBT yang beroperasi pada tegangan menengah dan tegangan tinggi. Hal ini disebabkan oleh sifat inverter multilevel kaskade yang modular, yang artinya inverter multilevel kaskade dapat dibangun dari modul-modul kecil inverter sesuai dengan kebutuhan [6].

Permasalahan yang berkaitan dengan inverter multilevel adalah bagaimana menentukan dan mengendalikan saklarsaklar semikonduktor daya untuk menghasilkan tegangan listrik AC yang berkualitas baik. Berbagai teknik pengendalian saklar semikonduktor daya telah dikembangkan, yaitu: Sinusoidal Pulse Width Modulation (SPWM) [7], Space Vector Pulse Width Modulation (SVPWM) [8] dan Selective Harmonic Elimination Pulse Width Modulation (SHEPWM).

Berbagai penelitian juga telah dilakukan untuk meningkatkan kinerja inverter multilevel, antara lain: a) eliminasi harmonisa menggunakan prakalkulasi fungsifungsi pensaklaran [9], b) mengembangkan topologitopologi inverter multilevel [10],[11] dan c) memperbaharui strategi kendali [12]. Penelitian lainnya [13]-[15], melaporkan bahwa inverter-inverter multilevel yang sudah dikembangkan berhasil beroperasi pada frekwensi rendah.

Selanjutnya dari hasil penelitian di [16]-[18] telah membuktikan bahwa teknik SHEPWM merupakan teknik yang paling andal digunakan untuk memperbaiki kualitas bentuk gelombang tegangan AC inverter multilevel. Teknik SHEPWM juga dapat digunakan untuk mengurangi besar frekwensi pensaklaran dan menurunkan THD inverter multilevel. Dengan demikian, inverter multilevel dengan teknik SHEPWM dapat dioperasikan pada frekwensi rendah dengan daya listrik besar [19]

Permasalahan utama yang berkaitan dengan teknik SHEPWM adalah bagaimana memperoleh sudut-sudut pensaklaran optimum dan mengaplikasikannya guna mengeliminasi komponen harmonisa tertentu dari 
tegangan AC yang dibangkitkan oleh inverter multilevel [20],[21].

Di dalam makalah ini, dijabarkan proses perancangan inverter multilevel kaskade dengan menggunakan teknik SHEPWM untuk mengeliminasi komponen harmonisa tertentu dari tegangan AC yang dibangkitkan. Sudut-sudut penyalaan optimum yang digunakan diekstrak dari hasil penelitian pada [22]. Selanjutnya analisis dan simulasi komputer dilakukan dengan menggunakan perangkat lunak PSPICE untuk memvalidasi hasil perancangan dan perhitungan secara teoritis.

\section{TINJAUAN PUSTAKA}

\section{A. Inverter Multilevel Kaskade}

Inverter multilevel kaskade tersusun dari $\mathrm{N}$ unit inverter satu-fasa dan $\mathrm{N}$ unit sumber tegangan DC. Setiap inverter satu-fasa memiliki 4 saklar semikonduktor $S_{1}, S_{2}, S_{3}$ dan $S_{4}$ serta terhubung ke sumber tegangan DC. Untuk sumber tegangan DC seimbang, maka $\mathrm{V}_{\mathrm{DC} 1}=\mathrm{V}_{\mathrm{DC} 2}=\ldots=\mathrm{V}_{\mathrm{DCN}}=$ $\mathrm{V}_{\text {DC }}$. Inverter-inveter satu-fasa tersebut tersambung secara seri sehingga membentuk inverter multilevel sebagaimana ditunjukkan dalam gambar 1.

Setiap inverter satu-fasa membangkitkan tegangan AC (lihat gambar 2). Selanjutnya penjumlahan tegangan AC yang dibangkitkan oleh masing-masing inverter satu-fasa $\left(\mathrm{V}_{\mathrm{AC} 1}+\mathrm{V}_{\mathrm{AC} 2}+\ldots+\mathrm{V}_{\mathrm{ACN}}\right)$ akan menghasilkan tegangan $\mathrm{AC}$ bertingkat seperti ditunjukkan dalam gambar 3. Dengan melalui proses pensaklaran yang tepat maka inverter multilevel mampu membangkitkan tegangan AC menengah hingga tinggi dari sumber tegangan DC rendah.

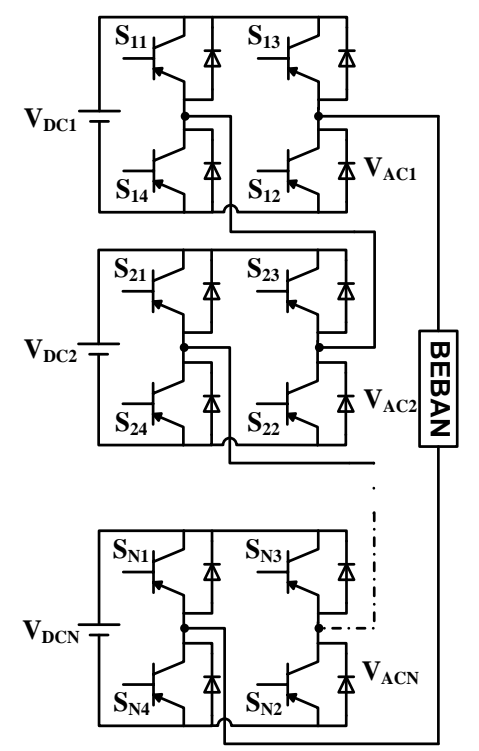

Gambar 1 Rangkaian inverter multilevel kaskade

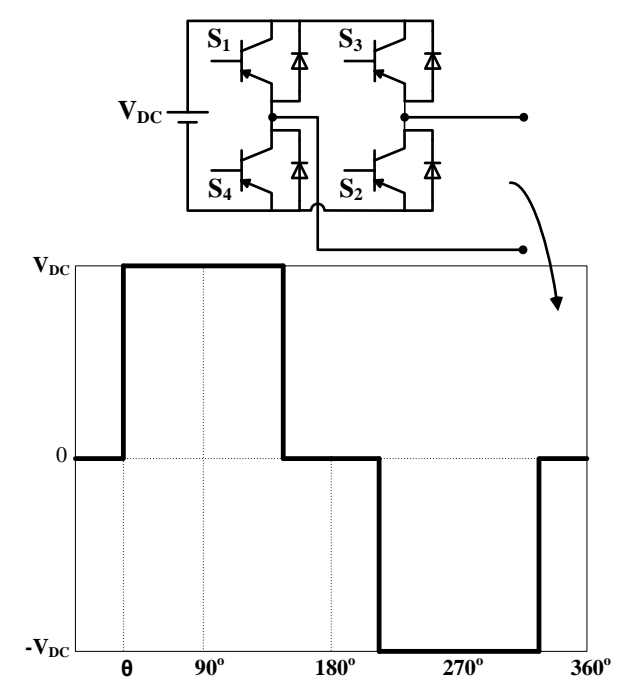

Gambar 2 Rangkaian dan tegangan AC yang dibangkitkan inverter satufasa pada sudut pensaklaran $\theta$

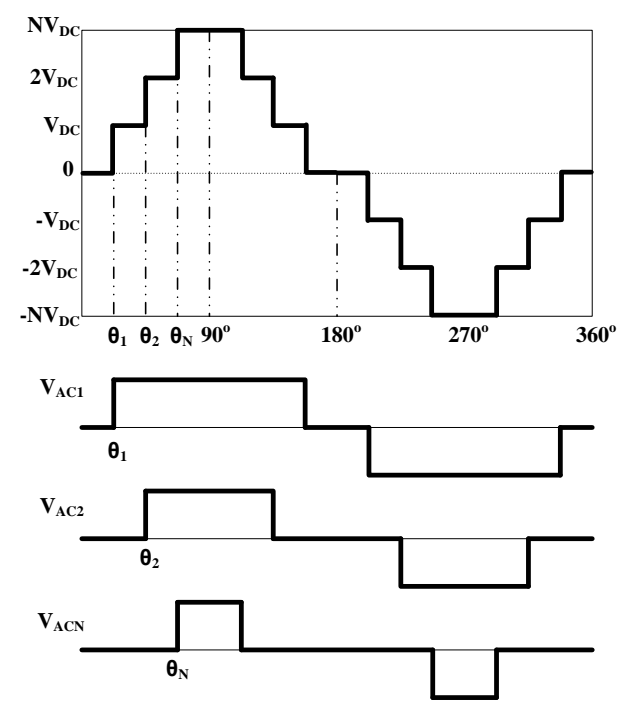

Gambar 3 Tegangan AC bertingkat yang dihasilkan inverter multilevel

\section{B. Teknik Selective HarmonicElimination Pulse Width Modulation}

Persamaan matematika untuk bentuk gelombang tegangan AC yang dibangkitkan oleh inverter multilevel, sebagaimana ditunjukkan dalam gambar 3, dapat direpresentasikan menggunakan deret Fourier [23], sebagai berikut:

$\mathrm{v}(\omega t)=V_{1} \sin (\omega t)+V_{2} \sin (2 \omega t)+\cdots+V_{N} \sin (N \omega t)$

Karena bentuk gelombang tegangan $\mathrm{AC}$ simetris, maka magnitudo komponen harmonisa genap $\left(\mathrm{V}_{2}, \mathrm{~V}_{4}, \mathrm{~V}_{6}, \ldots, \mathrm{V}_{2 \mathrm{~N}}\right)$ bernilai nol, sedangkan komponen harmonisa ganjil, yaitu: $\mathrm{V}_{1}, \mathrm{~V}_{3}, \mathrm{~V}_{5}, \ldots, \mathrm{V}_{(2 \mathrm{~N}-1)}$ dapat dihitung sebagai berikut:

$$
V_{n}=\frac{4 V_{D C}}{n \pi}\left[\sum_{k=1}^{N} \cos \left(n \theta_{k}\right)\right]
$$


Selective harmonic elimination pulse-width modulation atau disingkat SHEPWM adalah suatu teknik yang dapat digunakan untuk mengeliminasi komponen harmonisa tertentu dari tegangan AC yang dibangkitkan oleh inverter multilevel. Penerapan teknik SHEPWM dapat dilakukan apabila sudut-sudut pensaklaran untuk mengeliminasi komponen harmonisa-harmonisa tertentu sudah diketahui. Untuk mengeliminasi komponen harmonisa ke-3,5,7, ..., $(2 \mathrm{~N}-1)$, maka dibuat $\mathrm{V}_{3}=\mathrm{V}_{5}=\mathrm{V}_{7}=\ldots=\mathrm{V}_{(2 \mathrm{~N}-1)}=0$, sehingga sudut-sudut pensaklaran optimum dapat ditemukan dengan cara menyelesaikan serangkaian persamaan nonlinier sebagai berikut:

$$
\begin{aligned}
& \frac{4}{\pi M}\left[\sum_{k=1}^{N} \cos \left(\theta_{k}\right)\right]-1=0 \\
& V_{3}=\frac{4 V_{1}}{3 \pi M}\left[\sum_{k=1}^{N} \cos \left(3 \theta_{k}\right)\right]=0 \\
& V_{5}=\frac{4 V_{1}}{5 \pi M}\left[\sum_{k=1}^{N} \cos \left(5 \theta_{k}\right)\right]=0 \\
& V_{(2 N-1)}=\frac{4 V_{1}}{5 \pi M}\left[\sum_{k=1}^{N} \cos \left((2 N-1) \theta_{k}\right)\right]=0
\end{aligned}
$$

Di dalam persamaan (3) terdapat parameter pengendali tegangan AC yang dihasilkan oleh inverter multilevel, yaitu indeks modulasi atau $\mathrm{M}$, yang nilainya adalah rasio tegangan $\mathrm{AC}$ fundamental terhadap tegangan DC, atau dapat ditulis sebagai $\mathrm{M}=\mathrm{V}_{1} / \mathrm{V}_{\mathrm{DC}}$.

\section{HASIL DAN PEMBAHASAN}

Dengan menggunakan teknik SHEPWM, maka level inverter menentukan komponen harmonisa tertentu dari tegangan AC yang akan dieliminasi. Untuk meneliminasi harmonisa ke-3 maka dapat mempergunakan inverter 5level. Inverter 7-level mengeliminasi harmonisa ke-3 dan ke-5. Selanjutnya inverter 9-level mengeliminasi harmonisa ke 3, 5 dan 7. Semakin tinggi level inverter maka semakin banyak komponen harmonisa yang tereliminasi, namun memerlukan jumlah sudut pensaklaran yang lebih banyak pula.

\section{A. Inverter 5-Level}

Inverter 5-level terbentuk dari dua inverter satu-fasa yang tersambung secara seri. Rangkaian inverter 5-level ditunjukkan dalam gambar 4.

Supaya menghasilkan tegangan AC dengan harmonisa ke-3 tereliminasi maka diperlukan 2 sudut pensaklaran optimum, yaitu $\theta_{1}$ dan $\theta_{2}$. Untuk memperoleh 2 sudut pensaklaran tersebut maka harus menyelesaikan sistem persamaan nonlinier sebagai berikut:

$$
\begin{aligned}
& \frac{4}{\pi M}\left[\cos \left(\theta_{1}\right)+\cos \left(\theta_{2}\right)\right]=1 \\
& \frac{4}{3 \pi M}\left[\cos \left(3 \theta_{1}\right)+\cos \left(3 \theta_{2}\right)\right]=0
\end{aligned}
$$

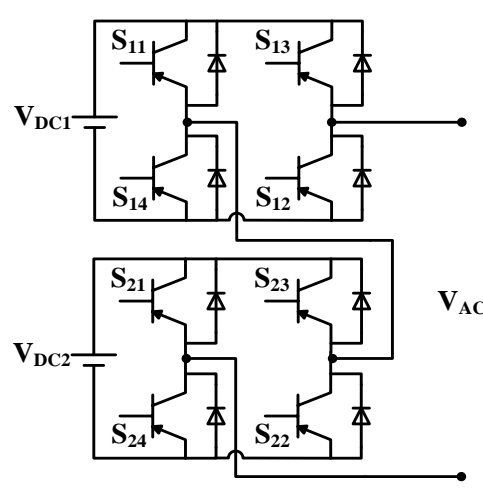

Gambar 4 Rangkaian inverter 5-level

Hasil penyelesaian sudut-sudut pensaklaran optimum berdasarkan laporan penelitian dalam [22], disajikan dalam Tabel 1.

Sebagai contoh, untuk $M=1,2$ maka sudut-sudut pensaklaran optimum adalah $\theta_{1}=27,0341^{\circ}$ dan dan $\theta_{2}=$ $87,0341^{\circ}$. Apabila frekwensi tegangan AC yang diinginkan adalah $50 \mathrm{~Hz}$, maka periode satu siklus pensaklaran adalah $\mathrm{T}=1 / 50=20 \mathrm{~ms}$. Selanjutnya waktu pensaklaran dapat dihitung, $\mathrm{t}_{1}=(27,0341 / 360) \times 20 \mathrm{~ms}=1,5019 \mathrm{~ms}$ dan $\mathrm{t}_{2}=$ $(87,0341 / 360) \times 20 \mathrm{~ms}=4,8352 \mathrm{~ms}$.

TABEL I

SUDUT-SUDUT PENYALAAN INVERTER 5-LEVEL

\begin{tabular}{|c|c|c|}
\hline $\mathbf{M}$ & $\boldsymbol{\theta}_{1}$ & $\boldsymbol{\theta} \mathbf{2}$ \\
\hline 1.10300 & 29.9897 & 89.9897 \\
\hline 1.11000 & 29.7795 & 89.7795 \\
\hline 1.20000 & 27.0341 & 87.0341 \\
\hline 1.30000 & 23.8795 & 83.8795 \\
\hline 1.40000 & 20.5927 & 80.5926 \\
\hline 1.50000 & 17.1427 & 77.1427 \\
\hline 1.60000 & 13.4879 & 73.4879 \\
\hline 1.70000 & 9.5685 & 69.5684 \\
\hline 1.80000 & 5.2928 & 65.2928 \\
\hline 1.90000 & 0.5070 & 60.5084 \\
\hline 1.95000 & 2.1566 & 57.8434 \\
\hline 2.00000 & 5.0804 & 54.9196 \\
\hline 2.10000 & 12.2216 & 47.7784 \\
\hline 2.20000 & 26.0211 & 33.9789 \\
\hline 2.20500 & 29.0308 & 30.9692 \\
\hline
\end{tabular}

Setelah diketahui waktu pensaklaran, maka rancangan pulsa-pulsa pensaklaran untuk inverter 5-level adalah sebagaimana ditunjukkan dalam gambar 5 dan 6 . 


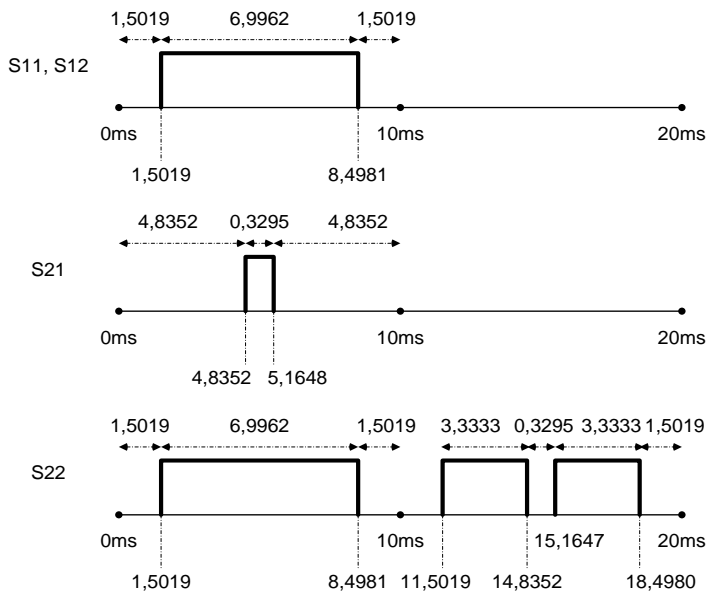

Gambar 5 Pulsa-pulsa pensaklaran untuk: $S_{11}, S_{12}, S_{21}$ dan $S_{22}$

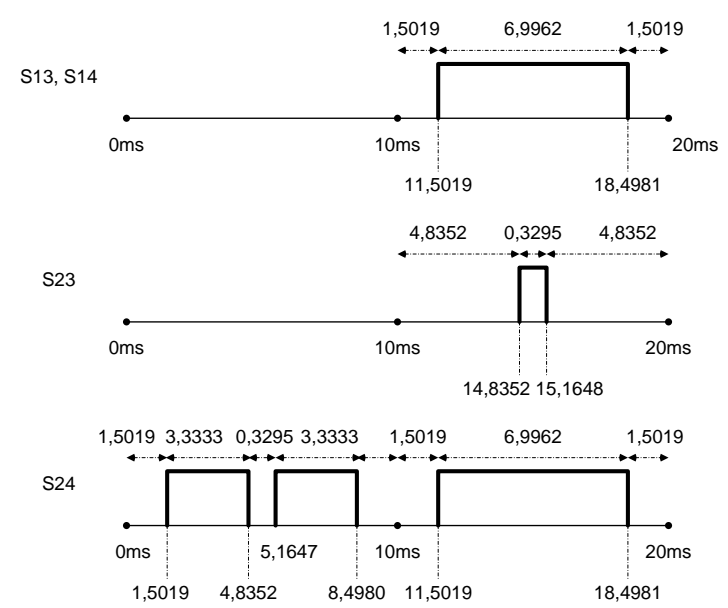

Gambar 6 Pulsa-pulsa pensaklaran untuk: $S_{13}, S_{14}, S_{23}$ dan $S_{24}$

Apabila $\mathrm{V}_{\mathrm{DC}}=100$ Volt maka tegangan $\mathrm{AC}$ yang dihasilkan oleh inverter 5-level pada $\mathrm{M}=1,2$ adalah seperti ditunjukkan dalam gambar 7 .

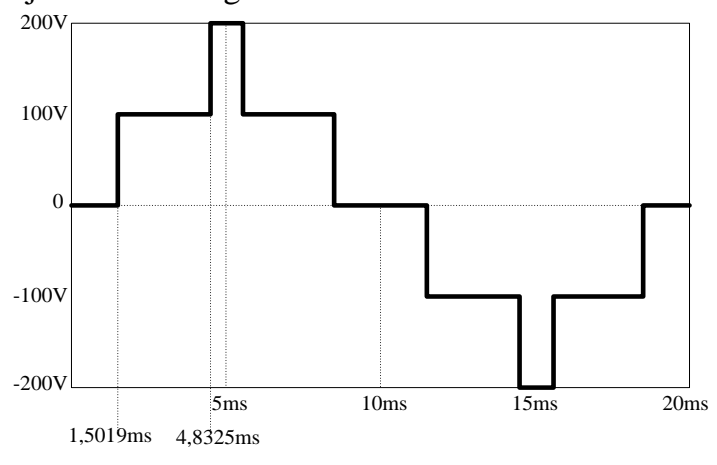

Gambar 7 Tegangan AC yang dihasilkan inverter 5-level

\section{B. Inverter 7-Level}

Tiga inverter satu-fasa membentuk inverter 7-level seperti ditunjukkan dalam gambar 8 .

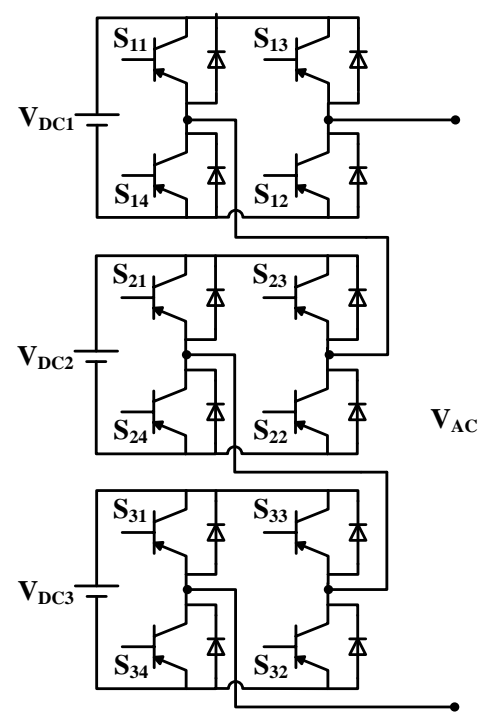

Gambar 8 Rangkaian inverter 7-level

Inverter 7-level memerluakan 3 sudut pensaklaran optimum untuk mengeliminasi harmonisa ke-3 dan 5. Sistem persamaan nonlinier untuk memperoleh $\theta_{1}, \theta_{2}$ dan $\theta_{3}$ adalah

$$
\begin{aligned}
& \frac{4}{\pi M}\left[\cos \left(\theta_{1}\right)+\cos \left(\theta_{2}\right)+\cos \left(\theta_{3}\right)\right]=1 \\
& \frac{4}{3 \pi M}\left[\cos \left(3 \theta_{1}\right)+\cos \left(3 \theta_{2}\right)+\cos \left(3 \theta_{3}\right)\right]=0 \\
& \frac{4}{5 \pi M}\left[\cos \left(5 \theta_{1}\right)+\cos \left(5 \theta_{2}\right)+\cos \left(5 \theta_{3}\right)\right]=0
\end{aligned}
$$

Sudut-sudut pensaklaran optimum [22] disajikan dalam Tabel 2.

Sebagai contoh, untuk $\mathrm{M}=2,1$ maka sudut-sudut pensaklaran optimum adalah $\theta_{1}=11,9849^{\circ}, \theta_{2}=47,9205^{\circ}$ dan $\theta_{3}=89,9443^{\circ}$. Untuk frekwensi tegangan AC $50 \mathrm{~Hz}$, maka waktu pensaklaran adalah $\mathrm{t}_{1}=(11,9849 / 360) \times 20 \mathrm{~ms}$ $=0,6658 \mathrm{~ms}, \mathrm{t}_{2}=(47,9205 / 360) \times 20 \mathrm{~ms}=2,6623 \mathrm{~ms}$ dan $\mathrm{t}_{3}$ $=(89,9443 / 360) \times 20 \mathrm{~ms}=4,9969 \mathrm{~ms}$.

TABEL III

SUDUT-SUDUT PENYALAAN INVERTER 7-LEVEL

\begin{tabular}{|c|c|c|c|}
\hline $\mathbf{M}$ & $\boldsymbol{\theta}_{\mathbf{1}}$ & $\boldsymbol{\theta}_{\mathbf{2}}$ & $\boldsymbol{\theta}_{\mathbf{3}}$ \\
\hline 2.09740 & 11.9998 & 47.9994 & 89.9996 \\
\hline 2.10000 & 11.9849 & 47.9205 & 89.9443 \\
\hline 2.20000 & 11.6983 & 44.8209 & 87.7458 \\
\hline 2.30000 & 12.0709 & 41.5484 & 85.4039 \\
\hline 2.40000 & 13.2264 & 38.0001 & 82.9074 \\
\hline 2.50000 & 15.3230 & 33.9581 & 80.2355 \\
\hline 2.60000 & 19.0907 & 28.5832 & 77.3550 \\
\hline 2.62000 & 20.4599 & 26.9223 & 76.7497 \\
\hline 2.63778 & 23.5211 & 23.6085 & 76.2025 \\
\hline- & - & - & - \\
\hline 3.06364 & 19.9694 & 20.1314 & 58.1703 \\
\hline 3.09000 & 12.2670 & 26.5350 & 56.2858 \\
\hline 3.10000 & 10.2314 & 27.8482 & 55.4971 \\
\hline 3.12000 & 5.1131 & 30.3335 & 53.7492 \\
\hline 3.12730 & 0.4077 & 31.2520 & 53.0364 \\
\hline 3.12734 & 0.1756 & 31.2569 & 53.0325 \\
\hline
\end{tabular}


Setelah diketahui waktu pensaklaran, maka rancangan pulsa-pulsa pensaklaran untuk inverter 7-level adalah sebagaimana ditunjukkan dalam gambar 9 dan 10 .
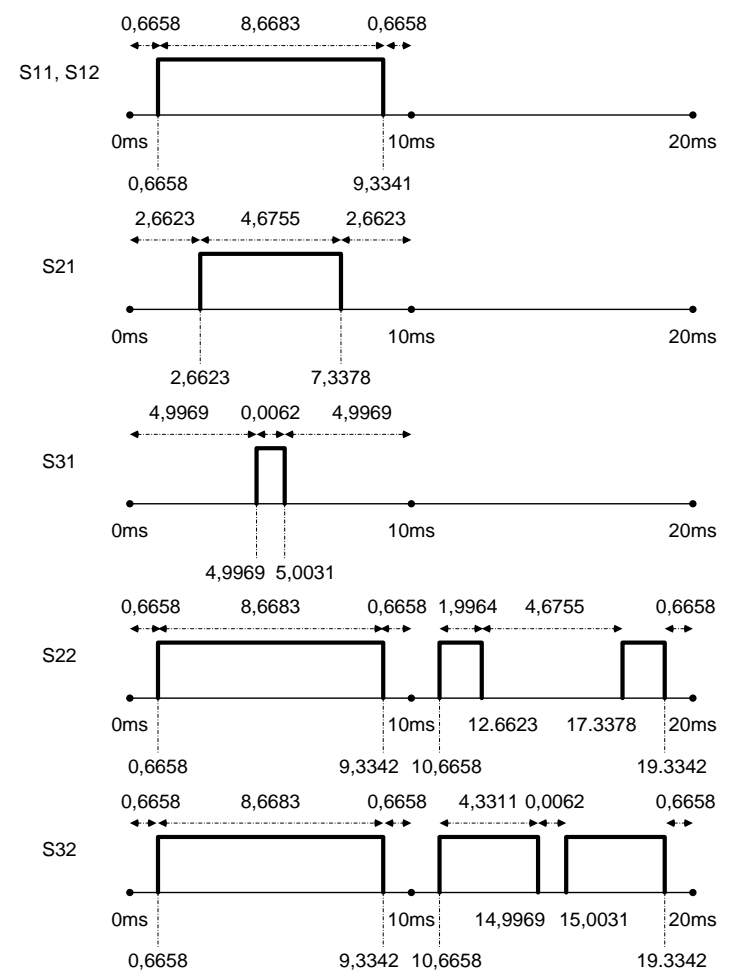

Gambar 9 Pulsa-pulsa pensaklaran untuk: $\mathrm{S}_{11}, \mathrm{~S}_{12}, \mathrm{~S}_{21}, \mathrm{~S}_{31}, \mathrm{~S}_{22}$ dan $\mathrm{S}_{32}$

Apabila $\mathrm{V}_{\mathrm{DC}}=100$ Volt maka tegangan $\mathrm{AC}$ yang dihasilkan oleh inverter 7-level pada $\mathrm{M}=2,1$ adalah seperti ditunjukkan dalam gambar 11

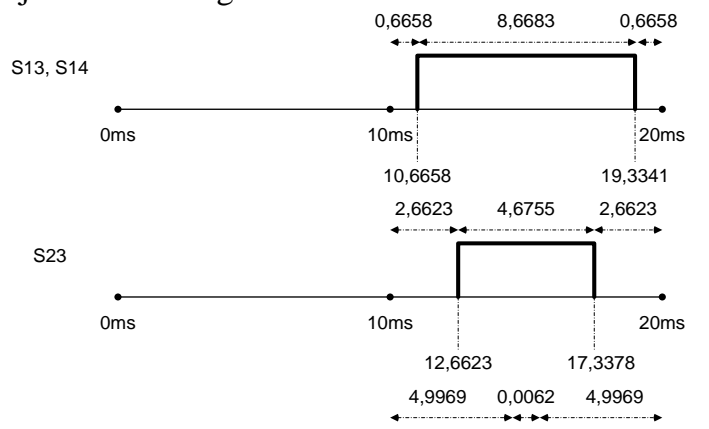

S33
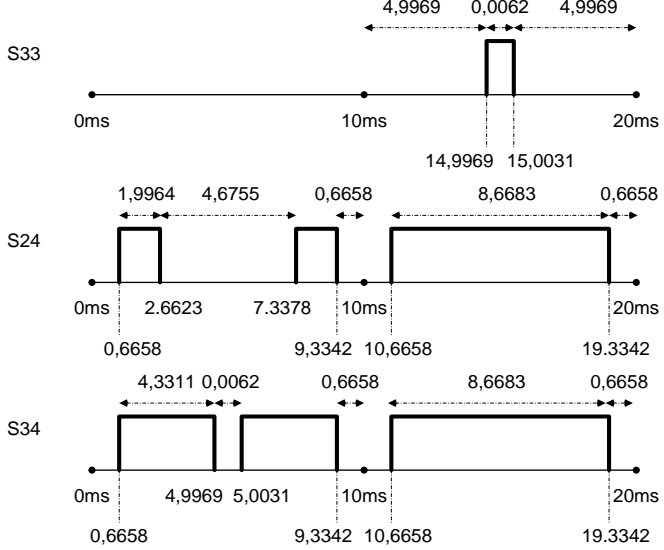

Gambar 10 Pulsa-pulsa pensaklaran untuk: $\mathrm{S}_{13}, \mathrm{~S}_{14}, \mathrm{~S}_{23}, \mathrm{~S}_{33}, \mathrm{~S}_{24}$ dan $\mathrm{S}_{34}$

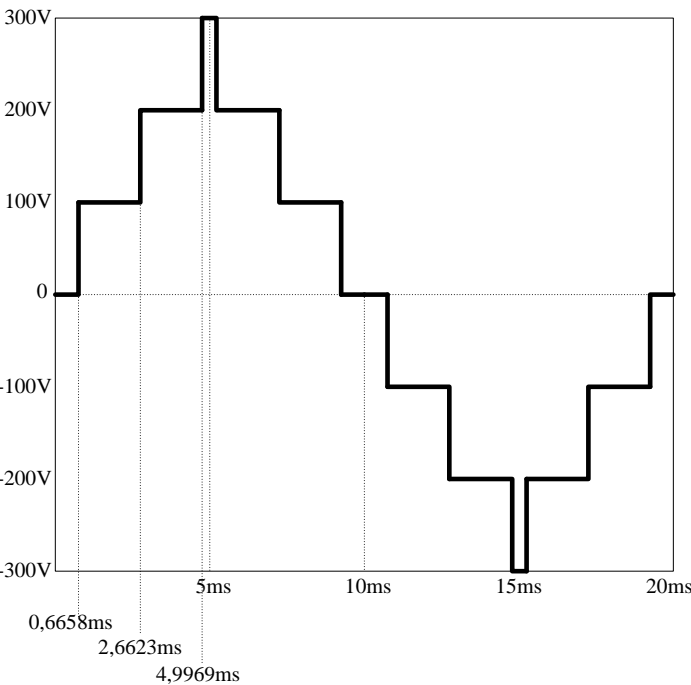

Gambar 11 Tegangan AC yang dihasilkan inverter 7-level

\section{Inverter 9-Level}

Inverter 9-level dibangun oleh 4 inverter satu-fasa yang tersusun secara seri. Inverter 9-level memerlukan 4 sudut pensaklaran optimum untuk mengeliminasi harmonisa ke3, 5 dan 7.

Sistem persamaan nonlinier untuk memperoleh $\theta_{1}, \theta_{2}, \theta_{3}$ dan $\theta_{4}$ adalah

$$
\frac{4}{\pi M}\left[\cos \left(\theta_{1}\right)+\cos \left(\theta_{2}\right)+\cos \left(\theta_{3}\right)+\cos \left(\theta_{4}\right)\right]=1
$$

$$
\begin{aligned}
& \frac{4}{3 \pi M}\left[\cos \left(3 \theta_{1}\right)+\cos \left(3 \theta_{2}\right)+\cos \left(3 \theta_{3}\right)+\cos \left(3 \theta_{4}\right)\right]=0 \\
& \frac{4}{5 \pi M}\left[\cos \left(5 \theta_{1}\right)+\cos \left(5 \theta_{2}\right)+\cos \left(5 \theta_{3}\right)+\cos \left(5 \theta_{4}\right)\right]=0 \\
& \frac{4}{7 \pi M}\left[\cos \left(7 \theta_{1}\right)+\cos \left(7 \theta_{2}\right)+\cos \left(7 \theta_{3}\right)+\cos \left(7 \theta_{4}\right)\right]=0
\end{aligned}
$$

Sudut-sudut pensaklaran optimum [22] disajikan dalam Tabel 3.

TABEL IIIII

SUdUT-SUdUT PENYALAAN INVERTER 9-LeVEL

\begin{tabular}{|c|c|c|c|c|}
\hline $\mathbf{M}$ & $\boldsymbol{\theta}_{\mathbf{1}}$ & $\boldsymbol{\theta}_{\mathbf{2}}$ & $\boldsymbol{\theta}_{\mathbf{3}}$ & $\boldsymbol{\theta}_{\mathbf{4}}$ \\
\hline 3.093000 & 11.6703 & 26.9363 & 56.0555 & 89.9995 \\
\hline 3.094000 & 11.6664 & 26.9269 & 56.0279 & 89.9824 \\
\hline 3.096000 & 11.6585 & 26.9083 & 55.9728 & 89.9481 \\
\hline 3.100000 & 11.6419 & 26.8720 & 55.8625 & 89.8793 \\
\hline 3.120000 & 11.5423 & 26.7068 & 55.3068 & 89.5322 \\
\hline 3.200000 & 10.8169 & 26.3546 & 53.0106 & 88.0910 \\
\hline 3.280000 & 9.41940 & 26.5741 & 50.5585 & 86.5634 \\
\hline 3.320000 & 8.39160 & 26.9191 & 49.2508 & 85.7659 \\
\hline 3.400000 & 5.25370 & 28.1202 & 46.3875 & 84.0986 \\
\hline 3.440000 & 2.03270 & 29.0199 & 44.7651 & 83.2263 \\
\hline 3.446000 & 0.73590 & 29.1763 & 44.5053 & 83.0931 \\
\hline 3.446800 & 0.24520 & 29.1978 & 44.4703 & 83.0753 \\
\hline 3.446900 & 0.00720 & 29.2004 & 44.4658 & 83.0730 \\
\hline- & - & - & - & - \\
\hline 4.089435 & 0.0563 & 24.9097 & 35.1107 & 60.8681 \\
\hline
\end{tabular}




\begin{tabular}{|c|c|c|c|c|}
\hline $\mathbf{M}$ & $\boldsymbol{\theta}_{\mathbf{1}}$ & $\boldsymbol{\theta}_{\mathbf{2}}$ & $\boldsymbol{\theta 3}$ & $\boldsymbol{\theta}_{\mathbf{4}}$ \\
\hline 4.090000 & 1.6703 & 24.7115 & 35.2312 & 60.8269 \\
\hline 4.100000 & 8.2859 & 21.0034 & 37.0578 & 60.0672 \\
\hline 4.105000 & 11.4165 & 18.3527 & 37.8488 & 59.6636 \\
\hline 4.107000 & 13.6124 & 16.3062 & 38.1531 & 59.4970 \\
\hline 4.107350 & 14.6905 & 15.2524 & 38.2059 & 59.4676 \\
\hline 4.107370 & 14.9626 & 14.9813 & 38.2082 & 59.4662 \\
\hline
\end{tabular}

\section{Simulasi PSPICE}

Untuk menghasilkan tegangan AC dari inverter 9-level, sebagai contoh parameter-parameter yang digunakan adalah: $\mathrm{V}_{\mathrm{DC}}=100$ Volt, $\mathrm{M}=3,2$, dan $\mathrm{f}=50 \mathrm{~Hz}(\mathrm{~T}=20 \mathrm{~ms})$. Dari Tabel 3, sudut-sudut penyalaan optimum untuk $M=$ 3.2 adalah: $\theta_{1}=10.8169^{\circ}, \theta_{2}=26.3546^{\circ}, \theta_{3}=53.0106^{\circ}$, dan $\theta_{4}=88.0910^{\circ}$.

Kode-kode PSPICE untuk simulasi inverter 9-level dengan menggunakan parameter-parameter tersebut adalah:

\section{*INVERTER SHEPWM 9 LEVEI}

PARAM Freq $=50 ;$ * Parameters: Freq $=$ output frequency

Vs1 1 la $100 \mathrm{~V} ;$ DC input voltage

Vs2 4 4a 100V; DC input voltage

Vs3 6 6a 100V; DC input voltage

Vs4 $88 \mathrm{a} 100 \mathrm{~V}$; DC input voltage

Rb11 $1112 \quad 50$

Vg11 123 PULSE(0 $10 \quad 0.6009 \mathrm{~ms}$ 1ns $1 \mathrm{~ns} 8.7981 \mathrm{~ms}\{1 /\{$ Freq $\})$ $\mathrm{Rb} 12171850$

Vg12 18 la PULSE (0 $10 \quad 0.6009 \mathrm{~ms}$ 1ns $1 \mathrm{~ns} 8.7981 \mathrm{~ms}\{1 /\{$ Freq $\})$

Rb13 $13 \quad 14 \quad 50$

Vg13 142 PULSE (0 $1010.6009 \mathrm{~ms}$ 1ns $1 \mathrm{~ns} 8.7981 \mathrm{~ms}\{1 /\{$ Freq $\})$

$\mathrm{Rb} 14151650$

Vg14 16 la PULSE(0 $1010.6009 \mathrm{~ms}$ 1ns $1 \mathrm{~ns} 8.7981 \mathrm{~ms}\{1 /\{$ Freq $\})$ )

$\mathrm{Rb} 21192050$

Vg21 202 PULSE(0 $101.4641 \mathrm{~ms}$ 1ns $1 \mathrm{~ns} 7.0717 \mathrm{~ms}$ \{1/\{Freq\}\})

VG22a 22a 0 PULSE ( $010 \quad 0.6009 \mathrm{~ms} 1 \mathrm{~ns} 1 \mathrm{~ns} 8.7981 \mathrm{~ms}\{1 /\{$ Freq $\})$ VG22b 22b 0 PULSE (0 $10 \quad 10.6009 \mathrm{~ms}$ 1ns $1 \mathrm{~ns} 0.8632 \mathrm{~ms}\{1 /\{$ Freq\} $\})$ VG22c 22c 0 PULSE (0 10 18.5359ms 1ns 1 ns $0.8632 \mathrm{~ms}\{1 /\{$ Freq $\})$ Eg220 2200 VALUE $\{$ V $(22 a)+V(22 b)+V(22 c)\}$

$\mathrm{Rb} 22252650$

Eg22 $264 a$ value $\{V(220)\}$

$\mathrm{Rb} 23 \quad 2122 \quad 50$

Vg23 225 PULSE (0 $1011.4641 \mathrm{~ms}$ 1ns $1 \mathrm{~ns} 7.0717 \mathrm{~ms}\{1 /\{$ Freq $\})$

VG24a $24 \mathrm{a} 0$ PULSE ( $010 \quad 0.6009 \mathrm{~ms}$ ins $1 \mathrm{~ns} 0.8632 \mathrm{~ms}\{1 /\{$ Freq $\})$ VG24b 24b 0 PULSE ( $010 \quad 8.5359 \mathrm{~ms}$ ins $1 \mathrm{~ns} 0.8632 \mathrm{~ms}\{1 /\{$ Freq $\})$ VG24c 24c 0 PULSE (0 $1010.6009 \mathrm{~ms}$ ins $1 \mathrm{~ns} 8.7981 \mathrm{~ms}$ (1/\{Freq\} $\})$ Eg240 2400 VALUE $\{\mathrm{V}(24 a)+\mathrm{V}(24 \mathrm{~b})+\mathrm{V}(24 \mathrm{c})\}$

Eg240 2400 VALC

Eg24 24 4a value $\{V(240)\}$

Rb31 $2728 \quad 50$

Vg31 285 PULSE (0 $102.9450 \mathrm{~ms}$ 1ns $1 \mathrm{~ns} 4.1099 \mathrm{~ms}\{1 /\{$ Freq $\}$ )

VG32a 32a 0 PULSE ( $010 \quad 0.6009 \mathrm{~ms} 1 \mathrm{~ns}$ 1ns $8.7981 \mathrm{~ms}\{1 /$ Freq $\})$ VG32b 32b 0 PULSE ( $01010.6009 \mathrm{~ms}$ 1ns $1 \mathrm{~ns} 2.3441 \mathrm{~ms}\{1 /\{$ Freq $\})$ VG32c 32c 0 PULSE (0 $1017.0550 \mathrm{~ms}$ ins $1 \mathrm{~ns} 2.3441 \mathrm{~ms}\{1 /$ Freq\} $\})$ Eg320 320 O VALUE $\{V(32 a)+V(32 b)+V(32 c)\}$

$\mathrm{Rb} 32 \quad 33 \quad 3450$

Eg32 34 6a value $\{V(320)\}$

$\mathrm{Rb} 332930 \quad 50$

Vg33 307 PULSE (0 $1012.9450 \mathrm{~ms}$ 1ns $1 \mathrm{~ns} 4.1099 \mathrm{~ms}\{1 /\{$ Freq $\})$

VG34a 34 a 0 PULSE ( $010 \quad 0.6009 \mathrm{~ms}$ 1ns $1 \mathrm{~ns} 2.3441 \mathrm{~ms}\{1 /\{$ Freq $\}$ \}) VG34b 34b 0 PULSE (0 $107.0550 \mathrm{~ms} 1 \mathrm{~ns} 1 \mathrm{~ns} 2.3441 \mathrm{~ms}$ \{1/\{Freq\} $\}$ VG34c 34c 0 PULSE (0 $1010.6009 \mathrm{~ms}$ 1ns $1 \mathrm{~ns} 8.7981 \mathrm{~ms}\{1 /\{$ Freq $\})$ Eg340 340 O VALUE $\{$ V $(34 a)+V(34 b)+V(34 c)\}$

Rb34 $3132 \quad 50$

Eg34 32 6a value $\{\mathrm{V}(340)\}$

$\mathrm{Rb} 4135 \quad 36 \quad 50$

Vg41 367 PULSE (0 $104.8939 \mathrm{~ms} 1 \mathrm{~ns} 1 \mathrm{~ns} 0.2121 \mathrm{~ms}\{1 /\{$ Freq $\}$ )

VG42a 42a 0 PULSE ( $010 \quad 0.6009 \mathrm{~ms}$ 1ns $1 \mathrm{~ns} 8.7981 \mathrm{~ms}\{1 /$ Freq\} $\})$ VG42b 42b 0 PULSE (0 $10 \quad 10.6009 \mathrm{~ms}$ 1ns $1 \mathrm{~ns} 4.2930 \mathrm{~ms}$ (1/ Freq\}\}) VG42c $42 \mathrm{c} 0$ PULSE (0 10 15.1061ms $1 \mathrm{~ns}$ 1ns $4.2930 \mathrm{~ms}$ (1/\{Freq\} $\})$ Eg420 420 O VALUE $\{\mathrm{V}(42 \mathrm{a})+\mathrm{V}(42 \mathrm{~b})+\mathrm{V}(42 \mathrm{c})\}$

$\begin{array}{lll}\text { Eg420 } & 420 & 0 \\ \text { Rb42 } 41 \quad 42 \quad 50\end{array}$

Eg42 428 a value $\{V(420)\}$

$\mathrm{Rb} 43373850$

Vg43 380 PULSE (0 $1014.8939 \mathrm{~ms} 1 \mathrm{~ns} 1 \mathrm{~ns} 0.2121 \mathrm{~ms}\{1 /\{$ Freq $\})$

VG44a 44a 0 PULSE (0 $10 \quad 0.6009 \mathrm{~ms}$ 1ns $1 \mathrm{~ns} 4.2930 \mathrm{~ms}\{1 /\{$ Freq $\})$ VG44b 44b 0 PULSE ( $010 \quad 5.1061 \mathrm{~ms}$ 1ns $1 \mathrm{~ns} 4.2930 \mathrm{~ms}\{1 /\{$ Freq $\}$ \}) VG44c $44 \mathrm{c} 0$ PULSE $(0 \quad 10 \quad 10.6009 \mathrm{~ms}$ ins $1 \mathrm{~ns} 8.7981 \mathrm{~ms}$ \{1/\{Freq\}\}) Eg440 4400 VALUE $\{\mathrm{V}(44 a)+V(44 b)+V(44 c)\}$

$\mathrm{Rb} 443940 \quad 50$

Eg44 40 8a value $\{V(440)\}$

D11 31 DMD; Diodes with model DMD

D12 1a 2 DMD

D14 la 3 DMD

D21 24 DMD

D22 4a 5 DMD

D23 54 DMD

D24 4a 2 DMD

D31 56 DMD

D32 $6 \mathrm{a} 7 \mathrm{DMD}$

D33 $7 \quad 6$ DMD

D34 6a 5 DMD

D41 78 DMD

D42 8a 0 DMD

D43 08 DMD

D44 8a 7 DMD

MODEL DMD D (IS=2.2E-15 BV=1800V TT=0) ;Diode model parameters

Q11 1113 QMOD ; BJTs with model QMOD

$\begin{array}{lllll}Q 12 & 2 & 17 & 1 \mathrm{a} & \mathrm{QMOD}\end{array}$

Q14 3 15 1a QMOD

221 $4 \begin{array}{llll}19 & 2 & \text { OMOD }\end{array}$

Q22 5 25 4a QMOD

$222 \quad 5 \quad 25$ 4a QMOD

Q24 $223 \quad 4 a$ QMOD

$031627 \quad 5$ OMOD

$\begin{array}{lllll}Q 31 & 6 & 27 & 5 & \text { QMOD } \\ \text { Q32 } & 7 & 33 & 6 a & \text { QMOD }\end{array}$

Q33 65297 OMOD

Q34 $5316 \mathrm{a}$ QMOD

O41 83577 OMOD

\begin{tabular}{lllll}
$Q 41$ & 8 & 35 & 7 & QMOD \\
\hline 42 & 0 & 41 & $8 a$ & OMOD
\end{tabular}

$\begin{array}{lllll}\text { Q42 } & 0 & 41 & 8 \mathrm{a} & \text { QMOD } \\ \mathrm{Q} 43 & 8 & 37 & 0 & \text { QMOD }\end{array}$

$\begin{array}{lllll}Q 43 & 8 & 37 & 0 & \text { QMOD } \\ 244 & 7 & 39 & 8 \mathrm{a} & \text { QMOD }\end{array}$

. MODEL QMOD NPN (IS=6.83E-14 BF=13 CJE=1PF CJC=607. $3 \mathrm{PF} \quad \mathrm{TF}=26.5 \mathrm{NS}$ ) R 301000

TRAN 0.1US 60MS OMS 0.1e-4 ; Transient Analysis

. FOUR $50 \mathrm{~Hz} 25 \mathrm{~V}(3,0)$

.OPTIONS ABSTOL=1UA CHGTOL=0.01nC ITL2=100 ITL4=150 RELTOL=0.1 VNTOL $=0.1$

. PROBE

END

Tegangan AC yang dibangkitkan oleh inverter 9-level hasil simulasi menggunakan PSPICE ditunjukkan dalam gambar 12. Sedangkan hasil analisis Fast Fourier Transform (FFT) [24] ditunjukkan dalam gambar 13.

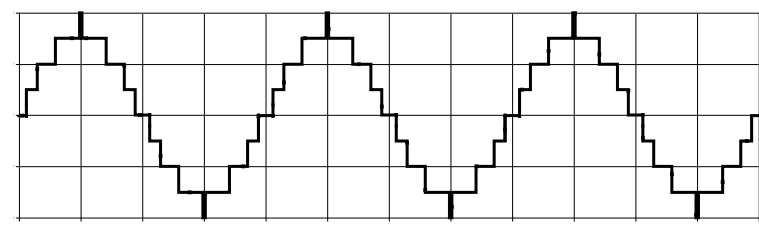

Gambar 12 Tegangan AC yang dihasilkan inverter 9-level

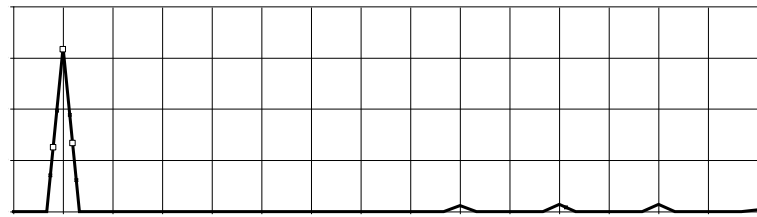

Gambar 13 Analisis FFT tegangan AC yang dihasilkan inverter 9-level

Nilai tegangan $\mathrm{AC}$ fundamental $\mathrm{V}_{1}=\mathrm{MxV}_{\mathrm{DC}}=3,2 \mathrm{x} 100$ $=320$ Volt. Berdasarkan analisis FFT dalam gambar 13, komponen harmonisa ke-3 $(150 \mathrm{~Hz})$, ke-5 $(250 \mathrm{~Hz})$ dan ke$7(350 \mathrm{~Hz})$ tereliminasi sama sekali. Sedangkan harmonisa 
tingkat-tinggi yang masih tersisa adalah: $\mathrm{V}_{9}=11,7328$ Volt, $\mathrm{V}_{11}=14,2621$ Volt, $V_{13}=14,2989$ Volt, $V_{15}=3,0544$ Volt, $V_{17}=10,6403$ Volt, $V_{19}=13,0515$ Volt, $V_{21}=1,0976$ Volt.

Setiap komponen harmonisa tingkat-tinggi semuanya bernilai kurang dari 5\%. Parameter untuk menentukan jumlah keseluruhan harmonisa disebut total harmonic distortion (THD) [25]. Dari hasil perhitungan dan simulasi, nilai THD dari tegangan AC pada gambar 12 adalah sebesar THD $=9.95 \%$.

\section{KESIMPULAN}

Inverter multilevel yang bekerja berdasarkan teknik SHEPWM memerlukan sudut-sudut pensaklaran yang tepat agar harmonisa-harmonisa tertentu yang ditarget tereliminasi sama sekali. Inverter 5-level bertujuan mengeliminasi komponen harmonisa ke-3, inverter 7-level mengeliminasi harmonisa ke-3 dan 5, sedangkan inverter 9-level mengeliminasi harmonisa ke-3, 5 dan, 7. Semakin tinggi level inverter semakin banyak komponen harmonisa yang dapat dieliminasi, namun memerlukan pulsa-pulsa pensaklaran yang semakin banyak pula.

Analisis hasil simulasi inverter multilevel menggunakan perangkat lunak PSPICE mampu menunjukkan keandalan inverter multilevel SHEPWM dalam mengeliminasi harmonisa-harmonisa tegangan AC yang dihasilkan.

\section{REFERENSI}

[1] A. Hiendro, Syaifurrahman, D. Triyanto, and Junaidi, "Solution trajectories for a single-phase programmed PWM inverter," TELKOMNIKA Indonesian Journal of Electrical Engineering, vol. 12, no. 7, pp. 5121-5128, 2014.

[2] B.P. Chandran, A.I. Selvakumar, and F.M.Mathew, "Integrating multilevel converters application on renewable energy sources-A survey," Journal of Renewable and Sustainable Energy, vol. 10, no. 6, p. $065502,2018$.

[3] Y. Lei, C.B. Barth, S. Qin, W.C. Liu, I. Moon, A. Stillwell, D. Chou, T. Foulkes, Z. Ye, Z. Liao, and R.C.N. Pilawa-Podgurski, “A 2-kW single-phase seven-level flying capacitor multilevel inverter with an active energy buffer," IEEE Transactions on Power Electronics, vol. 32, no. 11, pp. 8570-8581, 2017.

[4] R. Castillo, B. Diong, and P. Biggers, "Single-phase hybrid cascaded h-bridge and diode-clamp multilevel inverter with capacitor voltage balancing," IET Power Electronics, vol. 11, no.4, pp. 700-707, 2018.

[5] Y. Suresh, J. Venkataramanaiah, A.K. Panda, C. Dhanamjayulu, and P. Venugopal, "Investigation on cascade multilevel inverter with symmetric, asymmetric, hybrid and multi-cell configurations," Ain Shams Engineering Journal, vol. 8, no. 2, pp. 263-276, 2017.

[6] H. Akagi, "A review of developments in the family of modular multilevel cascade converters," IEEJ Tanssactions on Electrical and Electronic Engineering, vol. 13, pp. 1222-1235, 2018.

[7] B.A. Yomahudaya dan T. Sutikno, "Pembangkit sinyal SPWM untuk multilevel inverter satu fasa lima tingkat berbasis mikrokontroler ATmega32," Jurnal Ilmu Teknik Elektro Komputer dan Informatika (JITEKI), vol. 3, no. 2, pp. 73-81, 2017.

[8] F. Chen and W. Qiao, "A general space vector PWM scheme for multilevel inverters," in Proc. 2016 IEEE Energy Conversion Congress and Exposition (ECCE), Milwaukee, WI, 2016, pp. 1-6, doi: 10.1109/ECCE.2016.7854687.

[9] S.A. Amamra, K. Meghriche, A. Cherifi, and B. François, "Multilevel inverter topology for renewable energy grid integration," IEEE Transactions on Industrial Electronics, vol. 64 no. 11, pp. 8855-8866, 2017.

[10] M.B. Satti, A. Hasan, and M.I. Ahmad, "A new multilevel inverter topology for grid-connected photovoltaic systems," International Journal of Photoenergy, vol. 2018, pp. 1-9, 2018.
[11] H. Matalata and V. Yusiana, "New topology multilevel inverter type diode clamped five level single phase," IOP Conference Series Materials Science and Engineering, vol. 807, p. 012039, 2020.

[12] S. Lee and J. Kim, "Optimized modeling and control strategy of the single-phase photovoltaic grid-connected cascaded H-bridge multilevel inverter," Electronics, vol. 7, no.9, pp. 1-16, 2018.

[13] X. Tang, J. Zhang, Z. Liu, and M. Zhang, "A switching frequency optimized space vector pulse width modulation (SVPWM) scheme for cascaded multilevel inverters," Energies, vol. 10, no. 5, pp. 1$18,2017$.

[14] R. Ni, M. Sha, J.X. Guang, Y. Ding, and J. Chen, "Comparison of harmonics between SVPWM and SHEPWM," in Proc. The 3rd International Conference on Electrical and Information Technologies for Rail Transportation (EITRT), 2017, pp. 491-499, DOI: $10.1007 / 978-981-10-7986-3$-51.

[15] Z. Gong, Q. Cui, X. Zheng, P. Dai, and R. Zhu, "An improved imperialist competitive algorithm to solve the selected harmonic elimination pulse-width modulation in multilevel converters," Energies, vol. 11, no. 11, pp. 1-16, 2018.

[16] K.H. Law, W. P. Q. Ng, and W. K. Wong, "Flyback cascaded multilevel inverter Based SHE-PWM control for STATCOM applications," International Journal of Power Electronics and Drive System (IJPEDS), vol. 8, no. 1, pp. 100-108, 2017.

[17] P.L. Kamani and M.A. Mulla, "Univariate equation-based SHEPWM for multilevel inverter," Sädhanā, vol. 44, no. 5, pp. 1-5, 2019.

[18] M. Salman, I. Ul Haq, T. Ahmad, H. Ali, A. Qamar, A. Basit, M. Khan, and J. Iqbal, "Minimization of total harmonic distortions of cascaded H-bridge multilevel inverter by utilizing bio inspired AI algorithm," EURASIP Journal on Wireless Communications and Networking, vol. 66, pp. 1-12, 2020.

[19] M.S.A. Dahidah, G. Konstantinou, and V.G. Agelidis, ”A review of multilevel selective harmonic elimination PWM: Formulations, solving algorithms, implementation and applications," IEEE Transactions on Power Electronics, vol.30, no. 8, pp.4091-4106, 2015.

[20] S. Ahmad, M. Meraj, A. Iqbal, and I. Ashraf, "Selective harmonics elimination in multilevel inverter by a derivative-free iterative method under varying voltage condition," ISA Transaction, vol. 92, pp. 241-256, 2019.

[21] H. Behbahanifard, S. Abazari, and A. Sadoughi, "New scheme of SHE-PWM technique for cascade multilevel inverters with regulation of DC voltage sources," ISA Transaction, vol. 97, pp. 44-52, 2020.

[22] A. Hiendro, I. Yusuf, Junaidi, T.P. Wigyarianto, and Y.M. Simanjuntak, "Optimization of SHEPWM cascaded multilevel inverter switching patterns," International Journal of Power Electronics and Drive System (IJPEDS), vol. 11, no. 3, pp. 15701578,2020

[23] H. Gunawan, Analisis Fourier dan Wavelet, cetakan pertama, Bandung, Indonesia: Fakultas Matematika dan Ilmu Pengetahuan Alam ITB, 2017.

[24] M. Forman, "A fast fourier transform technique and its application to fourier spectroscopy," Journal de Physique Colloques, vol. 28, no. C2, pp. C2-58-C2-61, 1967.

[25] N. Prabaharan and K. Palanisamy, "A comprehensive review on reduced switch multilevel inverter topologies, modulation techniques and applications," Renewable and Sustainable Energy Reviews, vol. 76, pp. 1248-1282, 2017. 